Article

\title{
Anti-Obesity Effects of a Prunus persica and Nelumbo nucifera Mixture in Mice Fed a High-Fat Diet
}

\author{
Jungbin Song ${ }^{1} \mathbb{D}$, Jiye Kim ${ }^{2}$, Hyo Jin Park ${ }^{3}$ and Hocheol Kim ${ }^{1, *}$ \\ 1 Department of Herbal Pharmacology, College of Korean Medicine, Kyung Hee University, \\ 26 Kyungheedae-ro, Dongdaemun-gu, Seoul 02447, Korea; jbsong@khu.ac.kr \\ 2 Department of Herbal Pharmacology, College of Korean Medicine, Graduate School, Kyung Hee University, \\ 26 Kyungheedae-ro, Dongdaemun-gu, Seoul 02447, Korea; briskia@naver.com \\ 3 Korea Institute of Science and Technology for Eastern Medicine (KISTEM), NeuMed Inc., 88 Imun-ro, \\ Dongdaemun-gu, Seoul 02440, Korea; rnfyddyd@neumed.co.kr \\ * Correspondence: hckim@khu.ac.kr; Tel.: +82-2-961-0419
}

Received: 26 September 2020; Accepted: 2 November 2020; Published: 4 November 2020

check for updates

\begin{abstract}
Prunus persica and Nelumbo nucifera are major crops cultivated worldwide. In East Asia, both P. persica flowers and N. nucifera leaves are traditionally used for therapeutic purposes and consumed as teas for weight loss. Herein, we investigated the anti-obesity effects of an herbal extract mixture of P. persica and N. nucifera (HT077) and the underlying mechanism using a high-fat diet (HFD)-induced obesity model. Male C57BL/6 mice were fed a normal diet, HFD, HFD containing $0.02 \%$ orlistat (positive control), or HFD containing $0.1,0.2$, or $0.4 \%$ HT077 for 12 weeks. HT077 significantly reduced final body weights, weight gain, abdominal fat weights, liver weights, and hepatic levels of triglycerides and total cholesterol. HT077 also lowered glucose, cholesterol, alanine aminotransferase (ALT), aspartate aminotransferase (AST), and leptin levels and increased AST/ALT and adiponectin/leptin ratios and adiponectin levels. Real-time polymerase chain reaction analysis showed that HT077 decreased the expression of lipogenic genes and increased the expression of fatty acid oxidation-related genes in adipose tissue. Our results indicate that HT077 exerts anti-obesity effects and prevents the development of obesity-related metabolic disorders. These beneficial effects might be partially attributed to ameliorating adipokine imbalances and regulating lipid synthesis and fatty acid oxidation in adipose tissue.
\end{abstract}

Keywords: Prunus persica; Nelumbo nucifera; high-fat diet; adipokine; fatty acid oxidation; lipid synthesis; obesity

\section{Introduction}

The steady increase in overweight and obese individuals has become a serious health problem worldwide. Currently, it is estimated that nearly one-third of the world's population is overweight or obese [1]. Obese people are at a high risk for many serious diseases, including diabetes, cardiovascular diseases, nonalcoholic fatty liver disease (NAFLD), osteoarthritis, and cancers [2]. Obesity and related diseases not only damage a person's health and quality of life but also have become a socioeconomic burden. For the management of such conditions, lifestyle interventions, including a low-calorie diet, physical activity, and behavior therapy, are ideal, but motivation and adherence are not easy [3]. Pharmacological interventions for long-term use include orlistat, lorcaserin, liraglutide, phentermine-topiramate, and naltrexone-bupropion. These drugs are approved for moderately or severely obese patients with a body mass index (BMI) $\geq 30$ or BMI $\geq 27$ with comorbidities and have a high incidence of side effects [4]. Considering the limitations of conventional medication and the complex nature of the pathogenesis of obesity, more safe and effective novel approaches are required. 
Natural herbal products with anti-obesity effects have attracted much attention from researchers [5]. In East Asia, many traditional medicinal herbs are edible, and diet therapy using synergistic polyherbal formulations has been well accepted for a long time [6]. Given that the simultaneous modulation of multiple targets is required to manage multifactor diseases such as obesity [7], the use of synergistic polyherbal formulations will act on multiple targets, enhancing their anti-obesity effects. The introduction of a combination of edible herbs from traditional Asian medicine as dietary herbal therapy could be a promising approach for the treatment of obesity and associated disorders.

From these perspectives, we screened the anti-obesity effects of edible medicinal herbs used for weight and fat loss in East Asia. Through multiple screening processes using a high-fat diet (HFD)-induced obesity model, we revealed for the first time, to our knowledge, that the flowers of Prunus persica (L.) Batsch (family Rosaceae) effectively suppress abdominal fat accumulation and hyperglycemia in obese mice by reducing lipogenesis and increasing fatty acid oxidation in the liver [8]. Interestingly, P. persica has been shown more effective in reducing adiposity and associated hyperglycemia when combined with the leaves of Nelumbo nucifera Gaertn. (family Nelumbonaceae) in obese mice [9].

P. persica is cultivated worldwide for its fruit, namely peaches, and its flower has traditionally been utilized as a diuretic, purgative, and cosmetic in China and Korea; moreover, it is currently used as a weight loss tea $[8,10,11]$. P. persica flowers mainly contain phenolic compounds and flavonoids, and their major components include quercetin derivatives, kaempferol and its derivatives, and chlorogenic acid [12-15]. Their pharmacological actions are mostly beauty-related, including applications such as anti-obesity [8], skin-whitening [16], and the prevention of ultraviolet-induced photoaging [12,13]. In addition, purgative and prokinetic actions have been reported [10,14]. N. nucifera, commonly called lotus, is an aquatic crop, and its leaves have been widely used in Asia as a tea for weight loss, a food wrapper for cooking, and a traditional medicine for the management of obesity, hyperglycemia, and hyperlipidemia $[17,18]$. The bioactive constituents of $N$. nucifera leaves are mainly alkaloids, such as nuciferine and nornuciferine, which are responsible for its various pharmacological activities, including anti-obesity, anti-hyperlipidemia, anti-inflammatory, anti-hyperuricemic, sedative-hypnotic, and anxiolytic effects [17,19-21]. Although these two herbs have been used to manage obesity and associated metabolic disorders, the mixture of the two has not been well studied, and its effective dose and possible mechanisms of action remain unknown.

The present study investigated the anti-obesity effects of an herbal extract mixture of P. persica and N. nucifera (designated as HT077) and explored the underlying mechanisms using an HFD-induced obesity model. Male C57BL/6 mice were fed an HFD mixed with $0.1 \%, 0.2 \%$, or $0.4 \%$ HT077 for 12 weeks and their body weight, abdominal fat mass, spleen and liver weights, and serum biochemical profiles were assessed. We also measured hepatic triglyceride and total cholesterol contents and examined the expression levels of genes related to lipogenesis and fatty acid oxidation in adipose tissues.

\section{Materials and Methods}

\subsection{Sample Preparation}

HT077 is a mixture of water extracts of P. persica flowers and N. nucifera leaves. Dried P. persica flowers and N. nucifera leaves were purchased from Hebei Cao Mu Trade Co., Ltd. (Hebei, China) and Young Chang Medicinal Herbs Co. (Seoul, Korea), respectively, and were authenticated by Professor Hocheol Kim of the College of Korean Medicine, Kyung Hee University. P. persica was first extracted for $2 \mathrm{~h}$ with 20 volumes of distilled water at $100^{\circ} \mathrm{C}$ and then extracted for $2 \mathrm{~h}$ with 15 volumes of distilled water at $100^{\circ} \mathrm{C}$. N. nucifera was extracted for $3 \mathrm{~h}$ with 30 volumes of distilled water at $100{ }^{\circ} \mathrm{C}$. P. persica and N. nucifera extracts were individually cooled at room temperature, filtered, and concentrated under reduced pressure to 30 and 20 brix, respectively. Concentrated extracts were individually mixed with dextrin and spray-dried to yield powders (extraction yields of $49 \%$ and $22 \%$ for P. persica and $N$. nucifera, respectively). The extract powders of $P$. persica and $N$. nucifera were mixed at a ratio of 
57:43. Voucher specimens of the raw materials (no. 190,611,002 and 190,627,051) were deposited in the Herbarium of NeuMed Inc. (Seoul, Korea). Multiflorin B and nuciferine, the marker compounds of P. persica and N. nucifera, respectively [12,22], were quantified as $0.63 \mathrm{mg} / \mathrm{g}$ and $0.84 \mathrm{mg} / \mathrm{g}$ of dried HT077 extract, respectively, according to the high-performance liquid chromatography analysis.

\subsection{Animals and Experimental Design}

Three-week-old male C57BL/6 mice were purchased from Orient Bio Inc. (Seongnam-si, Gyeonggi-do, Korea) and acclimatized for 1 week before use. Mice were housed four per cage under controlled laboratory conditions of $23 \pm 1{ }^{\circ} \mathrm{C}, 55 \% \pm 5 \%$ humidity, and a $12 \mathrm{~h}$ light/dark cycle. After the acclimation period, the mice were randomly divided into six groups as follows: normal diet (ND), HFD control, HFD + orlistat (positive control), and HFD + 0.1, 0.2, or 0.4\% HT077 ( $n=8$ for ND, 16 for HFD, and 12 for the other four groups). The ND group was fed a rodent diet with $10 \mathrm{kcal} \%$ fat (cat. no. D12450B; Research Diets Inc., New Brunswick, NJ, USA) for 12 weeks, while the other HFD groups were fed a rodent diet with $60 \mathrm{kcal} \%$ fat (cat. no. D12492; Research Diets Inc.) with or without interventions. The positive control group received an HFD mixed with $0.02 \%$ orlistat, and the HFD + HT077 groups received an HFD mixed with $0.1,0.2$, or $0.4 \%$ HT077 extract. During the experimental period, mice were allowed ad libitum access to diet and distilled water. Mice were checked daily for clinical signs including general appearance, posture, consciousness, behavior, breathing, salivation, vomiting, and so forth, and body weight and food intake were measured twice per week. At the end of 12 weeks, the mice were fasted overnight and sacrificed under isoflurane anesthesia. Blood was collected from the inferior vena cava, and epididymal, perirenal, and mesenteric adipose tissues, liver, and spleen were dissected and weighed. The adipose tissues were identified and isolated according to Bagchi and MacDougald [23] for accurate and reproducible measurement. The relative organ weights were calculated on the basis of the fasted body weight. The blood samples were let stand for $30 \mathrm{~min}$ at room temperature and centrifuged at $3000 \mathrm{rpm}$ at $4{ }^{\circ} \mathrm{C}$ for $10 \mathrm{~min}$ to separate the serum. The adipose tissues, liver, and serum were stored at $-80^{\circ} \mathrm{C}$ before analysis. All experimental protocols were approved by the International Animal Care and Use Committee of the Korea Institute of Science and Technology for Eastern Medicine (approval no. KISTEM-IACUC-2019-004).

\subsection{Serum Biochemical Analysis}

Glucose, lipid, liver enzyme, and adipokine profiles were evaluated in serum. The levels of glucose, triglycerides, total cholesterol, aspartate aminotransferase (AST), and alanine aminotransferase (ALT) were analyzed using an automated clinical chemistry analyzer (DRI-CHEM NX700, Fujifilm Corp., Tokyo, Japan) according to the manufacturer's instructions. The levels of leptin and adiponectin were determined using Quantikine ${ }^{\circledR}$ ELISA kits (catalog no. MOB00 and MRP300, respectively; R\&D Systems, Inc., MN, USA) according to the manufacturer's instructions.

\subsection{Determination of Hepatic Lipid Content}

Lipids were extracted according to the method of Folch et al. [24] with slight modifications. Briefly, liver tissue $(100 \mathrm{mg})$ was homogenized in $800 \mu \mathrm{L}$ of methanol-chloroform solution $(1: 2, v / v)$ and $200 \mu \mathrm{L}$ of distilled water. The hepatic mixture was vortexed and centrifuged at 12,000 rpm for $10 \mathrm{~min}$. The lower phase of the mixture was separated and dried using nitrogen gas. The concentrations of triglyceride and total cholesterol in the liver were analyzed using commercial kits (catalog no. AM157S and AM202, respectively; Asan Pharmaceutical, Seoul, Korea).

\subsection{Real-Time Polymerase Chain Reaction (PCR) Analysis}

Total RNA was extracted from mesenteric adipose tissue using QIAzol lysis reagent (cat. no. 79306; Qiazen, Venlo, Netherlands) and reverse-transcribed to complementary DNA using a commercial reverse transcription kit (cat. no. 4368814; Applied Biosystems, Waltham, MA, USA) according to the manufacturer's instructions. PCR amplifications were 
performed on a StepOnePlus ${ }^{\mathrm{TM}}$ Real-Time PCR System (Applied Biosystems Inc., Bedford, MA, USA) using an SYBR Green PCR Master Mix (cat. no. 4367659; Applied Biosystems Inc., Bedford, MA, USA). The sequences of the sense and antisense primers were as follows: 5'-ACAGTCCAGCCTTTGAGGATAG-3' and '-GACACAGAAAGGCCAGTACACA-3' for sterol regulatory element-binding protein-1c (SREBP-1c); 5'-GGCAGCAGTTACACCACATAC-3' and 5'-TCATTACCTCAATCTCAGCATAGC-3' for acetyl-CoA carboxylase (ACC); 5'-GTACAGGC TGAAGGAGGACACT-3' and $5^{\prime}$-TGAGATGTGGATACCACCAGAG-3' for fatty acid synthase (FAS); $5^{\prime}$-CTGACCTACTACTTCAAGGGCAGT-3' and $5^{\prime}$-GGGAGTCTGTATGAATACCTCTGC-3' for stearoyl-CoA desaturase-1 (SCD-1); $5^{\prime}$-AGGAGCTCCAAGACTCTAGACAAC- $3^{\prime}$ and $5^{\prime}$-CAAAGTC TCTCTCAGGTAGCACTG-3' for peroxisome proliferator-activated receptor- $\gamma$ coactivator- $1 \alpha$ $(P G C-1 \alpha) ; \quad 5^{\prime}$-CAGTGGGGAGAGAGGACAGA-3' and $5^{\prime}$-AGTTCGG GAACAAGACGTTG-3' for peroxisome proliferator-activated receptor $\alpha(P P A R \alpha)$; 5'-CCAGGCTACAGTGGGACATT-3' and $5^{\prime}$-GAACTTGCCCATGTCCTTGT-3' for carnitine palmitoyltransferase-1 (CPT-1); $5^{\prime}$-AC AATGAATACGGCTACAGCAACAG-3' and 5'-GG TGGTCCAGGGTTTCTTACTCC- $3^{\prime}$ for glyceraldehyde-3-phosphate dehydrogenase. The relative gene expression levels were calculated by the $2^{-\Delta \Delta C t}$ method.

\subsection{Statistical Analysis}

Values are expressed as the mean \pm standard deviation (SD). One-way analysis of variance with Dunnett's post hoc test was performed to compare more than two groups, whereas independent $\mathrm{t}$-tests were performed to compare two groups. All analyses were performed using Prism 5 software (GraphPad Software, Inc., San Diego, CA, USA). Statistical significance was set at $p<0.05$.

\section{Results}

\subsection{Effects of HT077 on Body Weight and Food Consumption}

The body weights of animals in the HFD control group began to increase significantly compared with those in the ND group at week 4, and the difference between the two groups grew until the end of the study period (Figure 1a). Supplementation with $0.2 \%$ HT077 significantly reduced body weight at 4-8 weeks and tended to reduce body weight at $9-12$ weeks (not significant) compared with the HFD control group. Supplementation with $0.4 \%$ HT077 and $0.02 \%$ orlistat significantly decreased body weights at 4-12 and 1-12 weeks, respectively, compared with those in the HFD control group. At the end of the experiment, mice fed an HFD containing $0.4 \%$ HT077 showed markedly reduced body weight gains compared with those in the HFD control mice (both $p<0.001$, Figure 1b). HFD-fed control mice showed significantly lower food intake (weeks 0-4 and 8-12) or lower food intake (weeks 4-8) than ND-fed mice during the study period (Figure 1c). HFD-fed control mice had significantly higher energy intake (weeks 4-12) or higher energy intake (weeks 0-4) than ND-fed mice (Figure 1d). There was no significant difference in food intake and energy intake between the HFD + HT077 and HFD control groups. The food and energy intakes of the HFD $+0.02 \%$ orlistat group were significantly higher than those of the HFD control group for 12 weeks. In addition, no abnormal clinical signs of toxicity were observed in the HFD + HT077 group during the experimental period. 


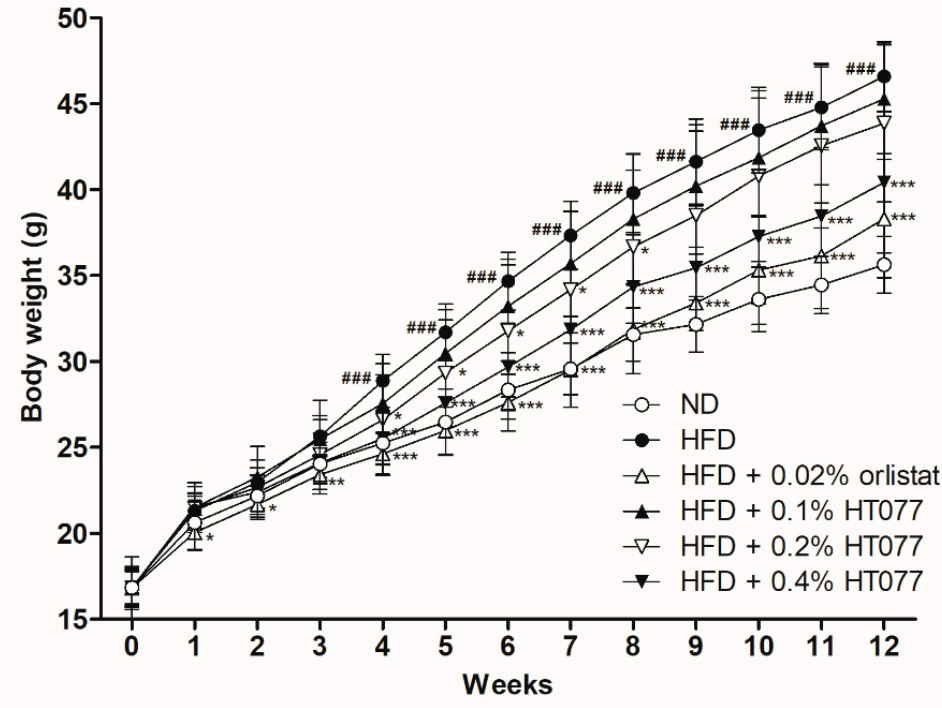

(a)

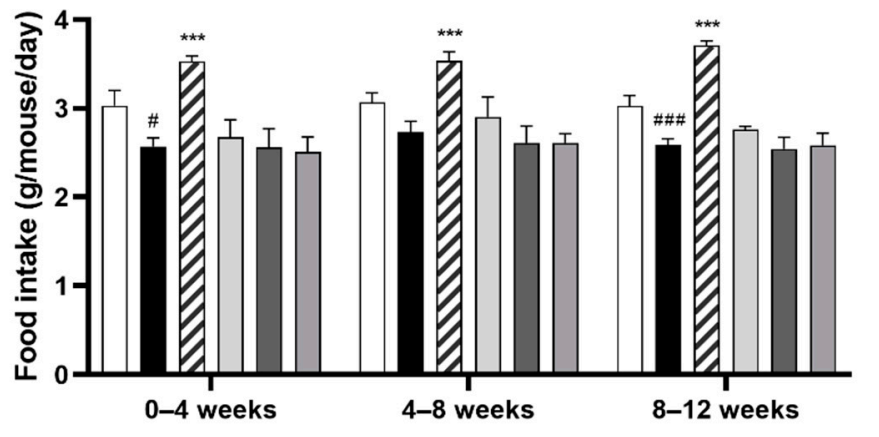

(c)

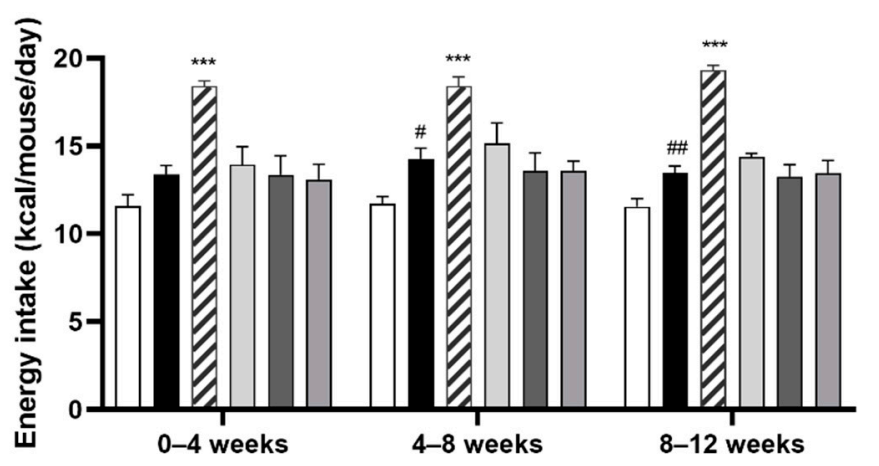

(d)

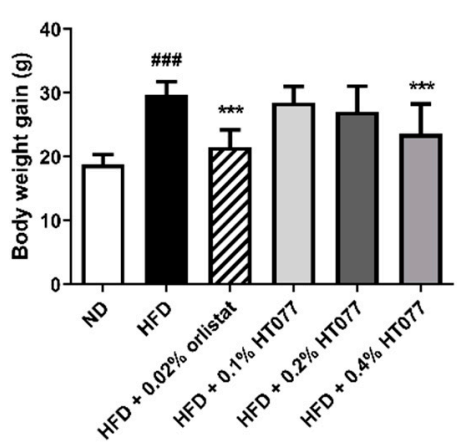

(b)

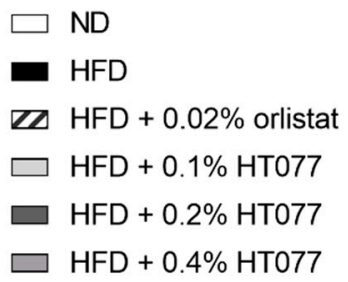

$\square$ ND

- HFD

(2) HFD $+0.02 \%$ orlistat

$\square \mathrm{HFD}+0.1 \% \mathrm{HT} 077$

$\square \mathrm{HFD}+0.2 \% \mathrm{HT} 077$

$\square$ HFD + 0.4\% HT077

Figure 1. Effects of an extract mixture of Prunus persica and Nelumbo nucifera (HT077) on body weight, and food and energy consumption in C57BL/6 mice fed a high-fat diet (HFD). (a) Body weight changes in mice that received either a normal diet (ND), HFD, HFD containing $0.02 \%$ orlistat, or HFD containing $0.1,0.2$, or $0.4 \%$ HT077 for 12 weeks. (b) Body weight gain for 12 weeks. Changes in (c) food intake and (d) energy intake over 12 weeks. All values are presented as the mean \pm SD ( $n=8$ for ND, 16 for HFD, and 12 for the other groups). ${ }^{\#} p<0.05,{ }^{\# \#} p<0.01$, and ${ }^{\# \#} p<0.001$ vs. ND group; ${ }^{*} p<0.05$, ** $p<0.01$, and ${ }^{* * *} p<0.001$ vs. HFD control group. 


\subsection{Effects of HT077 on Abdominal Fat, Liver, and Spleen Wet Weights}

The absolute and relative weights of total abdominal, perirenal, and mesenteric adipose tissue and the absolute epididymal adipose tissue weight were significantly increased in the HFD control group compared with those in the ND group, showing that 12 weeks of HFD feeding caused obesity (all $p<0.001$, Figure 2a-h). In contrast, supplementation with HT077 and orlistat significantly reduced the absolute and relative weights of perirenal, mesenteric, and total abdominal fat pad compared with those in the HFD control group (Figure 2c-h). HFD feeding increased the absolute liver weights compared with the those in the ND group ( $p<0.001$, Figure $2 \mathrm{i}$ ), whereas supplementation with $0.02 \%$ orlistat and $0.1 \%, 0.2 \%$, and $0.4 \%$ HT077 significantly reduced the absolute and relative liver weights compared with those in the HFD group (all $p<0.001$, Figure $2 \mathrm{i}, \mathrm{j})$. No difference was observed in spleen weights among the groups (Figure 2k,1).

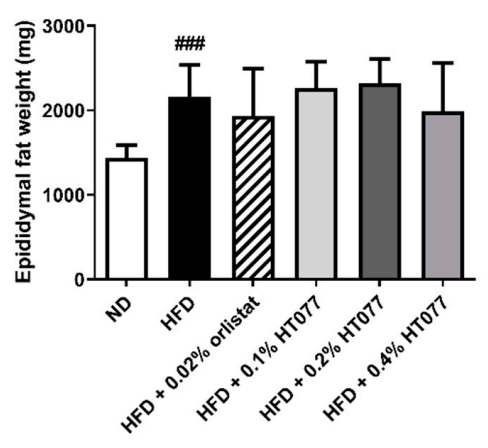

(a)

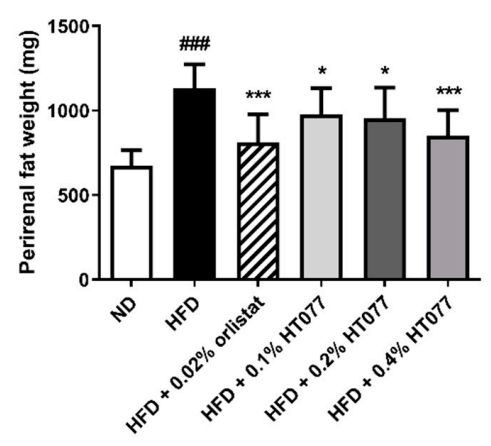

(c)

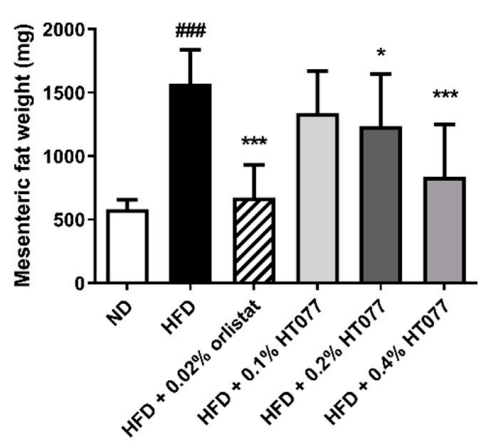

(e)

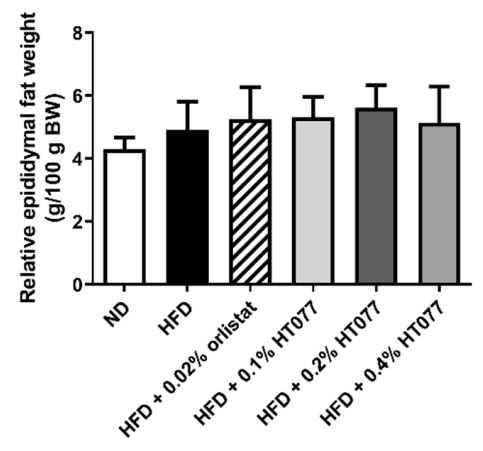

(b)

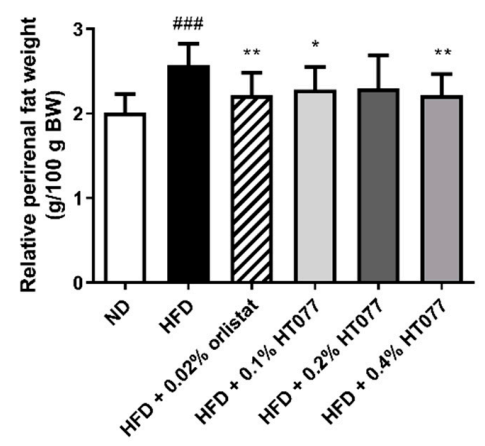

(d)

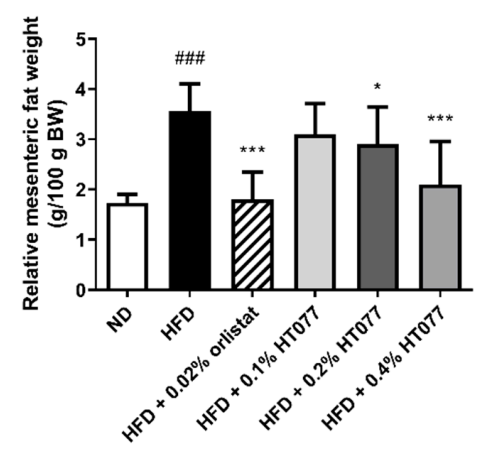

(f)

Figure 2. Cont. 


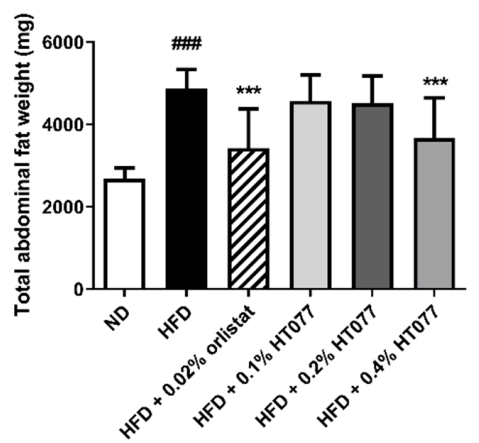

$(\mathrm{g})$

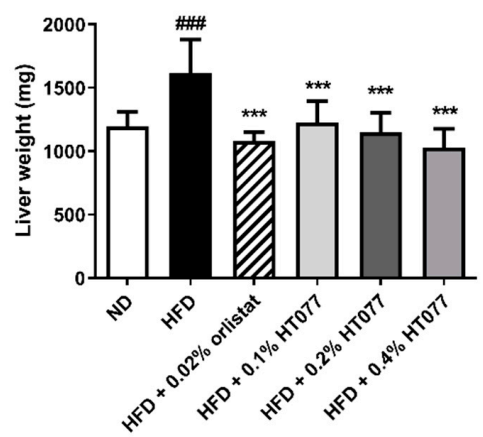

(i)

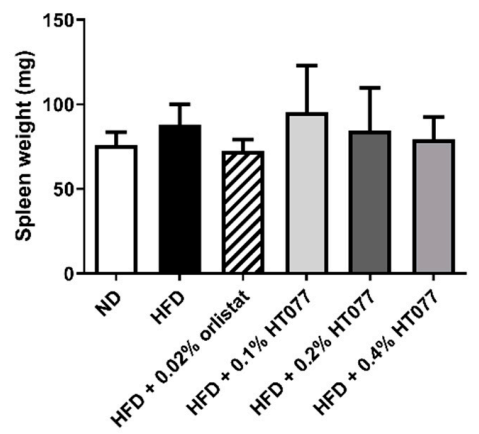

$(\mathbf{k})$

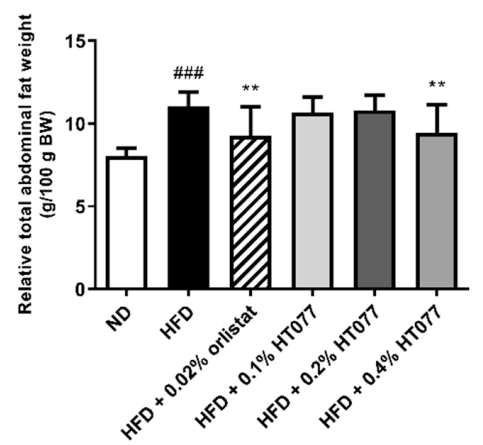

(h)

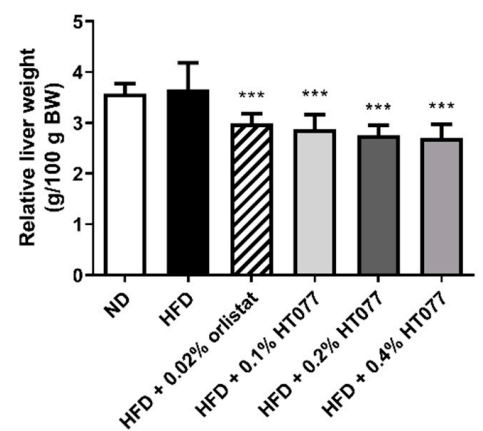

(j)

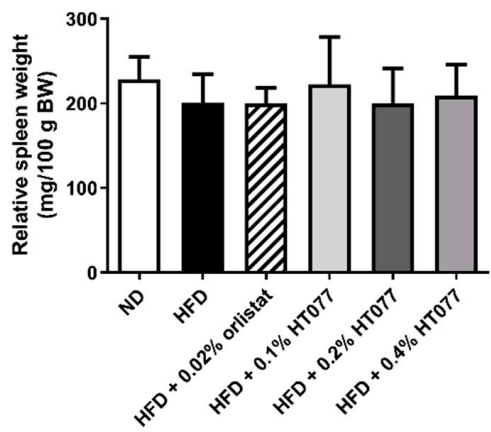

(1)

Figure 2. Effects of an extract mixture of Prunus persica and Nelumbo nucifera (HT077) on the absolute and relative weights of abdominal fat ( $\mathbf{a}-\mathbf{h})$, liver $(\mathbf{i}-\mathbf{j})$, and spleen $(\mathbf{k}-\mathbf{l})$ in C57BL/6 mice fed a high-fat diet (HFD). The absolute wet weights of white adipose tissues isolated from visceral regions including epididymal (a), perirenal (c), and mesenteric (e) deposits were measured. Total abdominal fat weights (g) are the sums of three individual fat depots $(\mathbf{a}, \mathbf{c}, \mathbf{e})$. The relative organ weight was calculated with respect to fasted body weight. Mice received either a normal diet (ND), HFD, HFD containing $0.02 \%$ orlistat, or HFD containing $0.1,0.2$, or $0.4 \%$ HT077 for 12 weeks. All values are presented as the mean $\pm \mathrm{SD}$ ( $n=8$ for ND, 16 for HFD, and 12 for the other groups). \#\# $p<0.001$ vs. ND group; ${ }^{*} p<0.05$ and ${ }^{* *} p<0.01,{ }^{* * *} p<0.001$ vs. HFD control group. BW, body weight.

\subsection{Effects of HT077 on Serum Levels of Glucose, Lipids, and Liver Enzymes}

HFD feeding significantly increased serum glucose levels compared with those in the ND group $(p<0.001$, Figure $3 a$ ). In contrast, supplementation with $0.02 \%$ orlistat and $0.1 \%, 0.2 \%$, and $0.4 \%$ HT077 significantly reduced glucose levels compared with those in the HFD control group 
(all $p<0.001$ ). No significant differences were observed in triglyceride levels among the groups (Figure 3b). Total cholesterol levels were not altered by HFD feeding but were significantly reduced by supplementation with $0.02 \%$ orlistat and $0.1 \%, 0.2 \%$, and $0.4 \%$ HT077 compared with those in the HFD control group (Figure 3c). Likewise, serum AST levels were not altered by HFD feeding but were significantly reduced by supplementation with $0.02 \%$ orlistat and $0.4 \%$ HT077 compared with those in the HFD control group (both $p<0.001$, Figure 3d). The HFD significantly elevated serum ALT levels and decreased the AST/ALT ratio compared with those in the ND group (both $p<0.001$, Figure 3e,f), whereas supplementation with $0.02 \%$ orlistat and $0.1 \%, 0.2 \%$, and $0.4 \%$ HT077 reversed these changes.

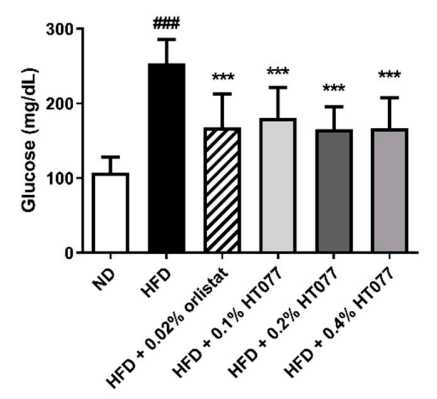

(a)

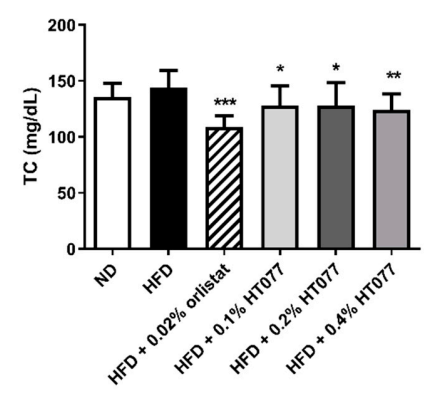

(c)

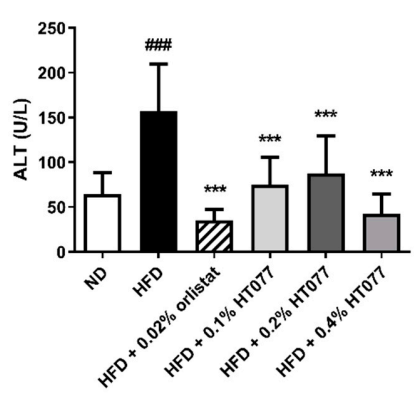

(e)

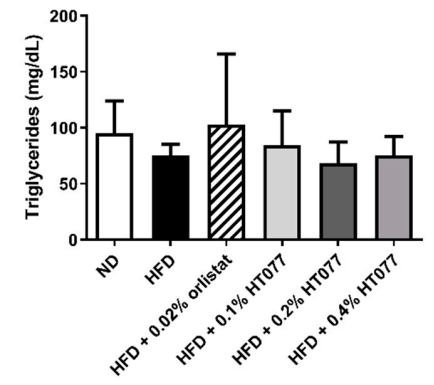

(b)

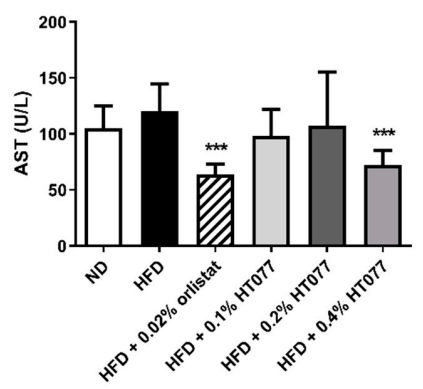

(d)

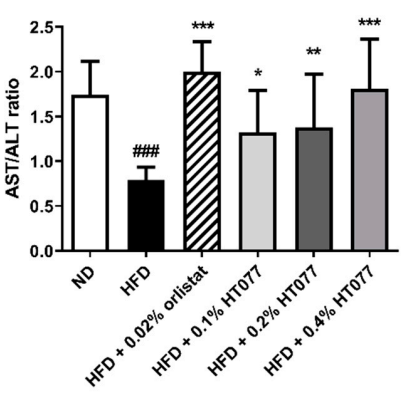

(f)

Figure 3. Effects of an extract mixture of Prunus persica and Nelumbo nucifera (HT077) on serum biochemical profiles in C57BL/6 mice fed a high-fat diet (HFD). The levels of glucose (a), triglycerides (b), total cholesterol (c), AST (d), and ALT (e), as well as the AST/ALT ratio (f), were measured. Mice received either a normal diet (ND), HFD, HFD containing $0.02 \%$ orlistat, or HFD containing 0.1, 0.2 , or $0.4 \%$ HT077 for 12 weeks. All values are presented as the mean \pm SD ( $n=8$ for ND, 16 for HFD, and 12 for the other groups). ${ }^{\# \#} p<0.001$ vs. ND group; ${ }^{*} p<0.05,{ }^{* *} p<0.01$, and ${ }^{* * *} p<0.001$ vs. HFD control group. ALT, alanine aminotransferase; AST, aspartate aminotransferase; TC, total cholesterol. 


\subsection{Effects of HT077on Serum Adipokine Concentrations}

Adiponectin levels tended to decrease after HFD feeding (statistically not significant), but significantly increased with $0.02 \%$ orlistat and $0.2 \%$ and $0.4 \%$ HT077 supplementation, as compared with levels in the HFD control group (Figure 4a). HFD feeding significantly increased serum leptin levels and decreased the adiponectin/leptin ratio compared with those in the ND group $(p<0.001$, Figure $4 \mathrm{~b}, \mathrm{c}$ ), whereas supplementation with $0.02 \%$ orlistat and $0.4 \%$ HT077 significantly reversed these changes.

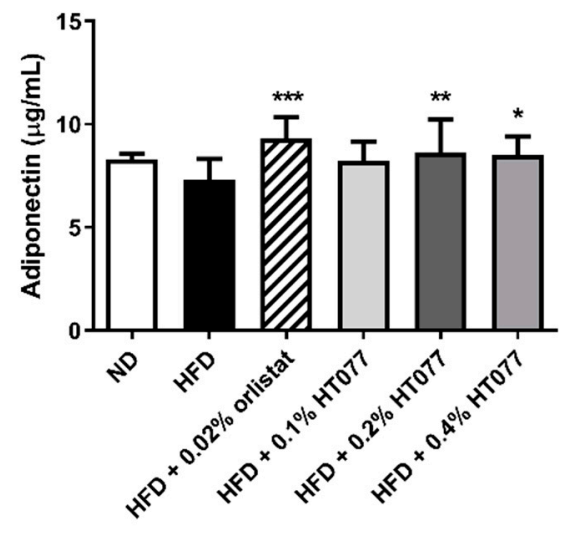

(a)

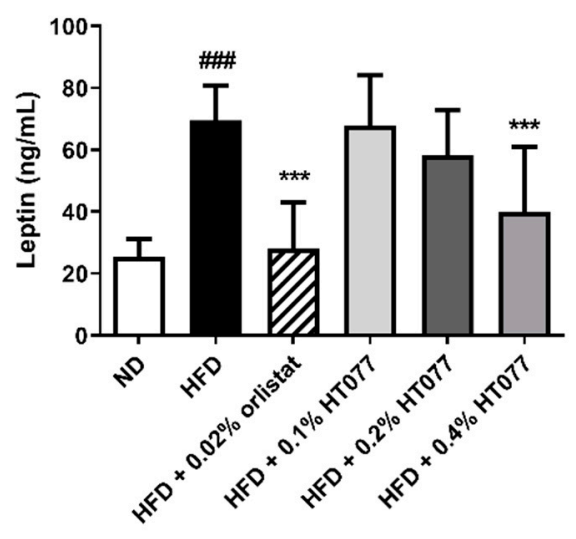

(b)

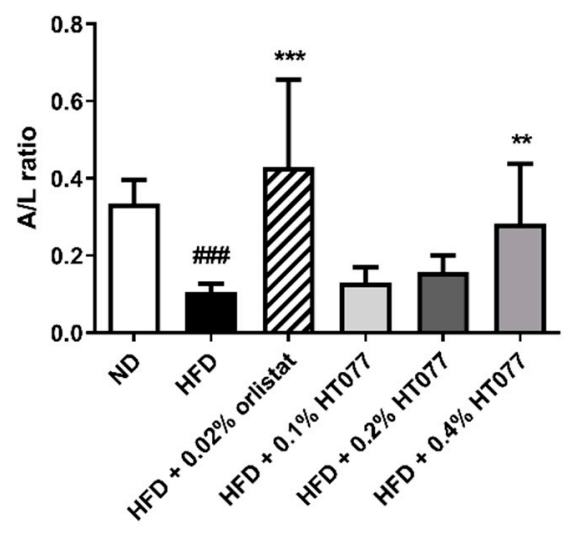

(c)

Figure 4. Effects of an extract mixture of Prunus persica and Nelumbo nucifera (HT077) on serum adiponectin (a) and leptin (b) levels and the adiponectin/leptin (A/L) ratio (c) in C57BL/6 mice fed a high-fat diet (HFD). Mice received either a normal diet (ND), HFD, HFD containing $0.02 \%$ orlistat, or HFD containing $0.1,0.2$, or $0.4 \%$ HT077 for 12 weeks. All values are presented as the mean \pm SD ( $n=8$ for ND, 16 for HFD, and 12 for the other groups). ${ }^{\# \#} p<0.001$ vs. ND group; ${ }^{*} p<0.05,{ }^{* *} p<0.01$, and ${ }^{* * *} p<0.001$ vs. HFD control group. 


\subsection{Effects of HT077on Hepatic Triglyceride and Total Cholesterol Contents}

Twelve weeks of HFD feeding significantly increased triglyceride levels in the liver $(p<0.05$, Figure 5a) but did not change total cholesterol levels (Figure 5b). Hepatic triglyceride levels were significantly reduced by supplementation with $0.4 \%$ HT077 $(p<0.05)$ but not $0.02 \%$ orlistat. Hepatic total cholesterol levels were significantly decreased by supplementation with $0.4 \%$ HT077 and $0.02 \%$ orlistat (both $p<0.01$ ).

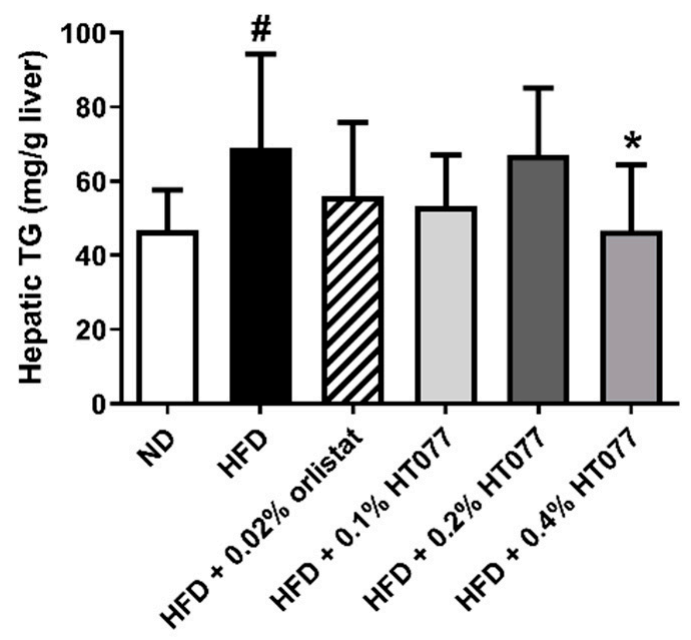

(a)

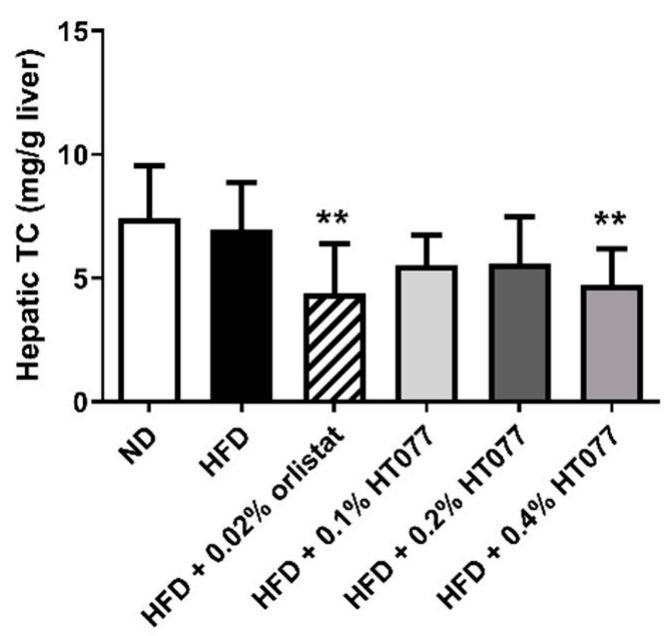

(b)

Figure 5. Effects of an extract mixture of Prunus persica and Nelumbo nucifera (HT077) on hepatic triglyceride (a) and total cholesterol (b) contents in C57BL/6 mice fed a high-fat diet (HFD). Mice received either a normal diet (ND), HFD, HFD containing $0.02 \%$ orlistat, or HFD containing $0.1,0.2$, or 0.4 HT077 for 12 weeks. All values are presented as the mean $\pm \mathrm{SD}(n=8$ for ND, 16 for HFD, and 12 for the other groups). ${ }^{\#} p<0.05$ vs. ND group. ${ }^{*} p<0.05$ and ${ }^{* *} p<0.01$ vs. HFD control group. TC, total cholesterol; TG, triglyceride.

\subsection{Effects of HT077on Lipogenesis and Fatty Acid Oxidation-Related Gene Expression in the Adipose Tissue}

To explore the possible mechanisms underlying the observed effects of HT077, gene expression related to lipid metabolism in mesenteric adipose tissue was compared between HFD and HFD + HT077 groups. Since a high dose $(0.4 \%)$ was the most effective at reducing adiposity, the HFD $+0.4 \%$ HT077 group was chosen for analysis. HT077 tended to decrease the expression levels of SREBP-1c in mesenteric adipose tissue compared with those in the HFD control mice ( $p=0.0574$, Figure 6a). The mRNA levels of $F A S$ and $S C D-1$ were significantly decreased in the HFD + 0.4\% HT077 group compared with those in the HFD control group $(p<0.001$ and $p<0.01$, respectively), whereas there was no difference in ACC mRNA levels between the two groups. The mRNA levels of $P G C-1 a$ and PPAR $\alpha$ were significantly increased in the HFD $+0.4 \%$ HT077 group compared with those in the HFD control group (both $p<0.05$, Figure 6b), whereas CPT1 mRNA levels were not different between the two groups. 


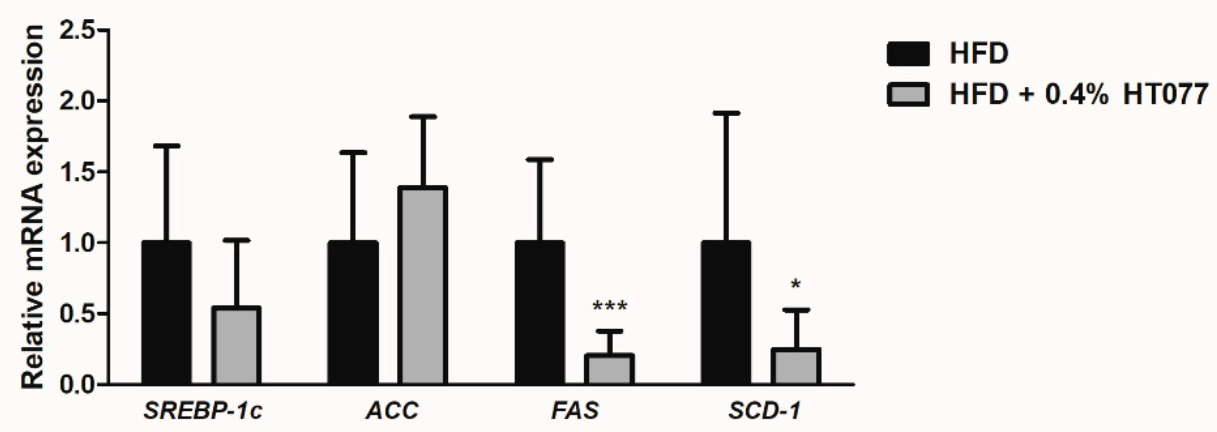

(a)

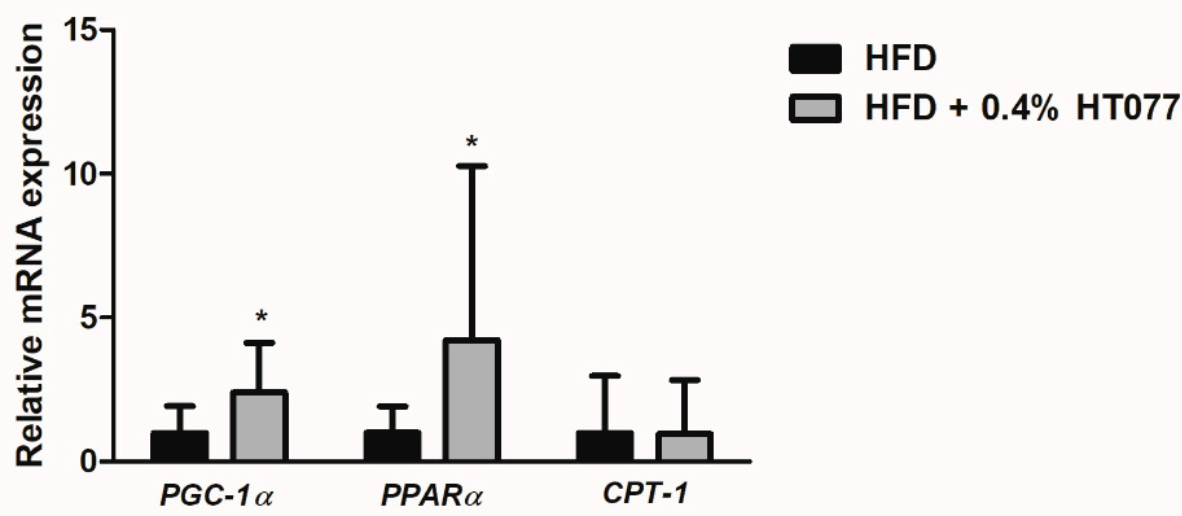

(b)

Figure 6. Effects of an extract mixture of Prunus persica and Nelumbo nucifera (HT077) on the expression of genes related to lipogenesis (a) and fatty acid oxidation (b) in the adipose tissue. C57BL/6 mice received a high-fat diet (HFD) or HFD containing $0.4 \%$ HT077 for 12 weeks. The mRNA expression levels of lipogenesis-related genes, including sterol regulatory element-binding protein 1c (SREBP-1c), acetyl-CoA carboxylase $(A C C)$, fatty acid synthase $(F A S)$, and stearoyl-CoA desaturase-1 (SCD-1), as well as fatty acid oxidation-related genes, including peroxisome proliferator-activated receptor- $\gamma$ coactivator- $1 \alpha$ $(P G C-1 \alpha)$, peroxisome proliferator-activated receptor $\alpha(P P A R \alpha)$, and carnitine palmitoyltransferase-1 $(C P T-1)$, were measured in the mesenteric white adipose tissue. All values are presented as the mean \pm SD ( $n=16$ for HFD and 12 for HFD + HT077 groups). The $y$-axis indicates relative gene expression normalized to that in the control group. ${ }^{*} p<0.05$ and ${ }^{* * *} p<0.001$ vs. HFD control group.

\section{Discussion}

This study revealed that the herbal mixture of P. persica and N. nucifera, which are commonly used as teas for weight loss in East Asia, reduced body weight and fat accumulation in the adipose tissue and livers of obese mice. In addition, HT077 improved circulating glucose, lipid, and adipokine profiles and regulated the expression of genes involved in lipid metabolism in adipose tissue.

HT077 reduced body weight and visceral fat in HFD-fed mice without noticeable changes in food and energy consumption. HFD-fed rodents had increased caloric consumption and decreased food intake compared with ND-fed rodents, which is possibly due to impaired satiation signaling, and leads to fat accumulation and weight gain [25]. It is well established that visceral fat is the main contributor to abdominal obesity and is related to an increased risk of metabolic dysfunction. Representative visceral fat deposits in rodents include those of the epididymal, perirenal, and mesenteric fat pad [26]. Among these, the accumulation of perirenal fat increases sodium reabsorption due to 
kidney compression and activates the renin-angiotensin-aldosterone system, causing the development of hypertension, insulin resistance, and atherosclerosis [27-29]. Mesenteric fat drained through portal circulation has higher lipolysis activities than nonportal adipose tissue, and its excessive accumulation is expected to increase free fatty acid flux to the liver, leading to fatty liver and insulin resistance [30,31]. Notably, HT077 at a high dose $(0.4 \%)$ reduced the perirenal and mesenteric fat weights by 61.4 and $74.4 \%$, respectively, compared with those in the control group. HT077 did not affect food and energy consumption, whereas orlistat, a lipase inhibitor, increased both parameters. In line with our results, intestinal lipase inhibition has been shown to increase appetite and food consumption, which may counteract the therapeutic effects of orlistat [32]. Our results indicate that HT077 exerts promising anti-obesity effects in the absence of a change in appetite.

Long-term HFD intake causes ectopic fat deposition in several organs other than adipose tissue, such as liver and spleen. HFD feeding for 12 weeks induced a significant increase in liver weight but not in spleen weight, which is consistent with previous results [33]. HT077 inhibited hepatic fat accumulation and liver weight gain in HFD-fed mice, along with decreased ALT and AST levels and an increased AST/ALT ratio. Hepatic fat accumulation arises from increased circulating fatty acid uptake and decreased $\beta$-oxidation in the liver, leading to NAFLD [34]. Furthermore, increased hepatic fat is known as an independent indicator of obesity-related metabolic complications [35]. NAFLD following HFD is denoted by the elevated leakage of liver enzymes from hepatocytes into the blood, with that of ALT being more prominent than that of AST, and by an AST/ALT ratio less than 1 [36,37], all of which are consistent with our results. P. persica and N. nucifera are known to inhibit fatty liver induced by HFD in animals by regulating hepatic lipogenesis [8,38-40]. Together with these previous findings, our results suggest that HT077 might prevent obesity-related fatty liver diseases.

Obesity is commonly a co-morbidity of glucose and lipid metabolism disorders. HFD consumption increases hepatic glucose output and decreases glucose uptake in peripheral tissues, resulting in hyperglycemia [41]. This increases insulin secretion and consequently activates hepatic lipogenesis and cholesterol excretion, leading to hyperlipidemia [41]. In this study, the serum levels of glucose and total cholesterol were significantly reduced after HT077 supplementation, indicating hypoglycemic and hypocholesterolemic activities. Previous studies have shown that $P$. persica and its major component multiflorin A reduce blood glucose levels in HFD-fed and glucose-loaded mice, respectively [8,42]. Further, N. nucifera improves glucose tolerance and insulin resistance in rodents fed an HFD [43,44] and shows anti-hyperglycemic activity in diabetic rats [45]. Moreover, we previously reported the synergistic effects of combined P. persica and N. nucifera on hypoglycemic activity in HFD-induced obese mice [9]. In addition, N. nucifera and its total flavonoids are known to improve lipid profiles of rats fed an HFD $[18,46]$. Our results, along with those of previous studies, suggest that HT077 might improve obesity-associated hyperglycemia and hypercholesterolemia.

Over the past few decades, it has been established that adipose tissue is not simply an energy reservoir but is an endocrine organ that secretes adipokines such as leptin and adiponectin. Leptin induces weight and fat loss by suppressing appetite and elevating energy expenditure through action in the hypothalamus [47]. Leptin resistance, marked by hyperleptinemia, occurs universally in human obesity and is a key feature of HFD-induced obesity in rodents [48]. It is known to exacerbate adiposity and hepatic triglyceride accumulation and impair the homeostasis of peripheral glucose and lipid metabolism [49]. Adiponectin has been shown to regulate peripheral glucose and fatty acid metabolism by increasing the insulin sensitivity of target organs, including the liver and muscle [50]. In obesity and metabolic syndrome, circulating adiponectin levels decrease and contribute to the development of insulin resistance [50]. In addition, the adiponectin/leptin ratio has recently been proposed as an indicator of adipose tissue dysfunction [51]. An increase in this ratio is better correlated with reduced insulin resistance than leptin or adiponectin alone [52]. Herein, HT077 significantly decreased circulating leptin levels and increased adiponectin levels and the adiponectin/leptin ratio. In support of our results, nuciferine, a major active alkaloid in $N$. nucifera leaf, reportedly reduces leptin and increases adiponectin levels in HFD-fed hamsters [53]. Our results indicate that improvements 
in leptin and adiponectin levels following HT077 administration might contribute to counteracting HFD-induced excessive lipid accumulation and abnormal glucose and lipid metabolism.

Adipose tissue plays an important role in the regulation of lipid metabolism and its metabolic functions include lipogenesis and fatty acid oxidation [54]. To better understand the mechanisms underlying the effects of HT077, we analyzed gene expression related to lipid metabolism in mesenteric adipose tissue. Mesenteric fat is known to be the most similar visceral tissue between humans and rodents because of its high vascularity and portal venous drainage $[55,56]$, and in this study, was the site where lipid accumulation was most inhibited by HT077. In C57BL/6 mice, HFD affects lipid metabolism in adipose tissue differently depending on the site of adipose tissue [57,58]. In mesenteric adipose tissue, lipogenic genes such as SREBP-1C, ACC, FAS, and SCD-1 are upregulated by an HFD compared with a ND, and inhibition of this upregulation exerts anti-obesity effects [58-61]. The expression of FAS and SCD-1 was significantly decreased by HT077 administration compared with that in the control mice. FAS and SCD-1 are central enzymes in de novo lipogenesis in adipose tissue [62]. FAS catalyzes the biosynthesis of saturated long-chain fatty acids from acetyl and malonyl coenzyme A and NADPH, whereas SCD-1 catalyzes the biosynthesis of monounsaturated fatty acids from their saturated fatty acid precursors [62]. Given that increased expression and activity of FAS and SCD-1 in adipose tissue contribute to the development of obesity and insulin resistance [63,64], decreased lipid synthesis through the inhibition of FAS and SCD-1 expression might contribute to the inhibitory effects of HT077 on adiposity and related metabolic disorders. Furthermore, an HFD upregulates the expression of fatty acid oxidation-related genes such as PGC-1 $\alpha, P P A R \alpha$, and CPT-1 in C57BL/6 mice and this upregulation attenuates fat accumulation in adipose tissue and liver $[57,58]$. HT077 increased the expression of PGC-1 $\alpha$ and PPAR $\alpha$ compared with that in the control mice. PGC- $1 \alpha$ and PPAR- $\alpha$ are key regulators of mitochondrial biogenesis. Their overexpression in adipocytes induces the expression of target genes involved in fatty acid oxidation, thereby inhibiting fat accumulation and improving insulin resistance $[65,66]$. Increased fatty acid oxidation in mesenteric fat induced by HT077 might contribute to the inhibition of free fatty acid influx into the liver, suppressing the development of fatty liver. Overall, our results suggest that the anti-obesity effects of HT077 are at least partially related to decreased lipogenesis and increased fatty acid oxidation in adipose tissue.

HT077 showed dose-dependent effects in reducing abdominal and hepatic fat accumulation and improving adipokine imbalances. Notably, HT077 at a high dose $(0.4 \%)$ inhibited fat accumulation similarly to orlistat. Glucose and total cholesterol levels were lowered similarly by all doses of HT077, and in particular, the hypoglycemic efficacy was comparable to that of orlistat. Our results overall suggest that high-dose HT077 therapy may provide beneficial effects as orlistat does. When calculated based on the food intake and body weight, the average daily doses of $0.1,0.2$, and $0.4 \%$ HT077 groups are approximately 90,180 , and $360 \mathrm{mg} / \mathrm{kg}$ of mouse body weight, respectively, and that of $0.02 \%$ orlistat group is $25 \mathrm{mg} / \mathrm{kg}$. The mouse dose of orlistat corresponds to a human equivalent dose of about $120 \mathrm{mg} /$ day for $60 \mathrm{~kg}$ person based on body surface area [67]. Considering that $90-180 \mathrm{mg} /$ day dosage of orlistat resulted in an 8.5-8.8\% reduction of initial body weight in a 6-month dose-ranging study of obese subjects [68], HT077 has a favorable anti-obesity efficacy.

Given that HT077 decreased FAS and SCD-1 expression and increased PGC-1 $\alpha$ and PPAR $\alpha$ expression in white adipose tissue (WAT), it is tempting to speculate that HT077 prevents HFD-induced weight gain by increasing energy expenditure via induction of WAT browning. Previous studies have shown that targeted deletion of FAS in adipose tissue induces brown fat-like adipocytes in WAT, increases energy expenditure, and decreases diet-induced obesity [69]. SCD-1 deficiency potentiates beige adipocyte formation and increases energy expenditure in HFD-fed mice [70]. In addition, overexpression of PGC- $1 \alpha$ and PPAR $\alpha$ induces brown fat feature in white adipocytes [71]. As browning of white fat significantly contributes to an increase in whole-body energy expenditure [72], HT077 is hypothesized to increase energy expenditure and this hypothesis requires further investigation to measure the energy expenditure of animals using metabolic cages, which was not examined in this study. In addition, the effects of HT077 on obesity-induced insulin resistance could be investigated since 
Nelumbo nucifera and its active constituent nuciferine have been shown to decrease serum insulin levels and homeostasis model assessment for insulin resistance index in HFD-induced obese rodents $[44,53]$.

\section{Conclusions}

Our results suggest that HT077 has anti-obesity effects and inhibits the development of obesity-related metabolic disorders such as fatty liver, hyperglycemia, and hyperlipidemia. These effects might be partially mediated by an improvement in blood leptin and adiponectin concentrations and the regulation of lipid synthesis and fatty acid oxidation in adipose tissue. Our results support the potential health benefits of HT077 in managing obesity and related metabolic diseases.

Author Contributions: Conceptualization, J.S. and H.K.; methodology, J.S., H.J.P. and H.K.; investigation, J.S., J.K. and H.J.P.; writing—original draft preparation, J.S. and J.K.; writing-review and editing, J.S. and H.K.; visualization, J.S.; supervision, H.K.; project administration, H.K.; funding acquisition, H.K. All authors have read and agreed to the published version of the manuscript.

Funding: This work was supported by the Bio-Synergy Research Project (NRF-2012M3A9C4048795) of the Ministry of Science, ICT and Future Planning through the National Research Foundation.

Conflicts of Interest: The authors declare no conflict of interest.

\section{References}

1. Collaborators, G.B.D.O.; Afshin, A.; Forouzanfar, M.H.; Reitsma, M.B.; Sur, P.; Estep, K.; Lee, A.; Marczak, L.; Mokdad, A.H.; Moradi-Lakeh, M.; et al. Health effects of overweight and obesity in 195 countries over 25 years. New Engl. J. Med. 2017, 377, 13-27. [CrossRef]

2. Pi-Sunyer, X. The medical risks of obesity. Postgrad. Med. 2009, 121, 21-33. [CrossRef] [PubMed]

3. Kwon, H.N.; Nam, S.S.; Park, Y.K. Effect on 12-week intensive dietary and exercise program on weight reduction and maintenance in obese women with weight cycling history. Clin. Nutr. Res. 2017, 6, 183-197. [CrossRef] [PubMed]

4. Apovian, C.M.; Aronne, L.J.; Bessesen, D.H.; McDonnell, M.E.; Murad, M.H.; Pagotto, U.; Ryan, D.H.; Still, C.D.; Endocrine, S. Pharmacological management of obesity: An endocrine Society clinical practice guideline. J. Clin. Endocrinol. Metab. 2015, 100, 342-362. [CrossRef] [PubMed]

5. Karri, S.; Sharma, S.; Hatware, K.; Patil, K. Natural anti-obesity agents and their therapeutic role in management of obesity: A future trend perspective. Biomed. Pharmacother. 2019, 110, 224-238. [CrossRef] [PubMed]

6. Liu, J.Y.; Chen, X.X.; Tang, S.C.W.; Lao, L.X.; Sze, S.C.W.; Lee, K.F.; Zhang, K.Y.B. Edible plants from traditional Chinese medicine is a promising alternative for the management of diabetic nephropathy. J. Funct. Foods 2015, 14, 12-22. [CrossRef]

7. Scotti, L.; Monteiro, A.F.M.; de Oliveira Viana, J.; Mendonca Junior, F.J.B.; Ishiki, H.M.; Tchouboun, E.N.; Santos, R.; Scotti, M.T. Multi-target drugs against metabolic disorders. Endocr. Metab. Immune Disord. Drug Targets 2019, 19, 402-418. [CrossRef] [PubMed]

8. Song, J.; Kim, Y.S.; Kim, L.; Park, H.J.; Lee, D.; Kim, H. Anti-obesity effects of the flower of Prunus persica in high-fat diet-induced obese mice. Nutrients 2019, 11, 2176. [CrossRef]

9. Kim, H.; Song, J.; Lee, Y. Compositions for Preventing, Improving or Treating Obesity and Metabolic Diseases Comprising Combined Extracts of Peach Blossom and Lotus Leaf. KR patent registration number 10-1886299, 1 August 2018.

10. Han, W.; Xu, J.D.; Wei, F.X.; Zheng, Y.D.; Ma, J.Z.; Xu, X.D.; Wei, Z.G.; Wang, W.; Zhang, Y.C. Prokinetic activity of Prunus persica (L.) Batsch flowers extract and its possible mechanism of action in rats. Biomed. Res. Int. 2015, 2015, 569853. [CrossRef]

11. Kwak, C.S.; Yang, J. Prevention effect of Prunus persica Flos extract from reactive oxygen species generation and matrix metalloproteinases production induced by UVB irradiation in human skin cells. Asian J. Beauty Cosmetol. 2016, 14, 179-190. [CrossRef]

12. Kim, Y.H.; Yang, H.E.; Park, B.K.; Heo, M.Y.; Jo, B.K.; Kim, H.P. The extract of the flowers of Prunus persica, a new cosmetic ingredient, protects against solar ultraviolet-induced skin damage in vivo. J. Cosmet. Sci. 2002, 53, 27-34. [PubMed] 
13. Kwak, C.S.; Yang, J.; Shin, C.Y.; Chung, J.H. Topical or oral treatment of peach flower extract attenuates UV-induced epidermal thickening, matrix metalloproteinase-13 expression and pro-inflammatory cytokine production in hairless mice skin. Nutr. Res. Pract. 2018, 12, 29-40. [CrossRef]

14. Takagi, S.; Yamaki, M.; Masuda, K.; Kubota, M.; Minami, J. Studies on the purgative drugs. III. On the constituents of the flowers of Prunus persica Batsch. Yakugaku Zasshi 1977, 97, 109-111. [CrossRef] [PubMed]

15. Liu, J.C.; Jiao, Z.G.; Yang, W.B.; Zhang, C.L.; Liu, H.; Lv, Z.Z. Variation in phenolics, flavanoids, antioxidant and tyrosinase inhibitory activity of peach blossoms at different developmental stages. Molecules 2015, 20, 20460-20472. [CrossRef] [PubMed]

16. Murata, K.; Takahashi, K.; Nakamura, H.; Itoh, K.; Matsuda, H. Search for skin-whitening agent from Prunus plants and the molecular targets in melanogenesis pathway of active compounds. Nat. Prod. Commun. 2014, 9, 185-188. [CrossRef]

17. Ono, Y.; Hattori, E.; Fukaya, Y.; Imai, S.; Ohizumi, Y. Anti-obesity effect of Nelumbo nucifera leaves extract in mice and rats. J. Ethnopharmacol. 2006, 106, 238-244. [CrossRef] [PubMed]

18. Liu, S.; Li, D.; Huang, B.; Chen, Y.; Lu, X.; Wang, Y. Inhibition of pancreatic lipase, alpha-glucosidase, alpha-amylase, and hypolipidemic effects of the total flavonoids from Nelumbo nucifera leaves. J. Ethnopharmacol. 2013, 149, 263-269. [CrossRef] [PubMed]

19. Ye, L.H.; He, X.X.; You, C.; Tao, X.; Wang, L.S.; Zhang, M.D.; Zhou, Y.F.; Chang, Q. Pharmacokinetics of nuciferine and n-nornuciferine, two major alkaloids from Nelumbo nucifera leaves, in rat plasma and the brain. Front. Pharmacol. 2018, 9, 902. [CrossRef]

20. Wang, M.X.; Liu, Y.L.; Yang, Y.; Zhang, D.M.; Kong, L.D. Nuciferine restores potassium oxonate-induced hyperuricemia and kidney inflammation in mice. Eur. J. Pharmacol. 2015, 747, 59-70. [CrossRef]

21. Yan, M.Z.; Chang, Q.; Zhong, Y.; Xiao, B.X.; Feng, L.; Cao, F.R.; Pan, R.L.; Zhang, Z.S.; Liao, Y.H.; Liu, X.M. Lotus leaf alkaloid extract displays sedative-hypnotic and anxiolytic effects through GABAA receptor. J. Agric. Food Chem. 2015, 63, 9277-9285. [CrossRef]

22. Do, T.C.; Nguyen, T.D.; Tran, H.; Stuppner, H.; Ganzera, M. Analysis of alkaloids in Lotus (Nelumbo nucifera Gaertn.) leaves by non-aqueous capillary electrophoresis using ultraviolet and mass spectrometric detection. J. Chromatogr. A 2013, 1302, 174-180. [CrossRef]

23. Bagchi, D.P.; MacDougald, O.A. Identification and dissection of diverse mouse adipose depots. J. Vis. Exp. 2019, 149, e59499. [CrossRef] [PubMed]

24. Folch, J.; Lees, M.; Sloane Stanley, G.H. A simple method for the isolation and purification of total lipides from animal tissues. J. Biol. Chem. 1957, 226, 497-509.

25. Melhorn, S.J.; Krause, E.G.; Scott, K.A.; Mooney, M.R.; Johnson, J.D.; Woods, S.C.; Sakai, R.R. Acute exposure to a high-fat diet alters meal patterns and body composition. Physiol. Behav. 2010, 99, 33-39. [CrossRef]

26. Chusyd, D.E.; Wang, D.; Huffman, D.M.; Nagy, T.R. Relationships between rodent white adipose fat pads and human white adipose fat depots. Front. Nutr. 2016, 3, 10. [CrossRef]

27. Hall, J.E.; do Carmo, J.M.; da Silva, A.A.; Wang, Z.; Hall, M.E. Obesity, kidney dysfunction and hypertension: Mechanistic links. Nat. Rev. Nephrol. 2019, 15, 367-385. [CrossRef]

28. Ricci, M.A.; Scavizzi, M.; Ministrini, S.; De Vuono, S.; Pucci, G.; Lupattelli, G. Morbid obesity and hypertension: The role of perirenal fat. J. Clin. Hypertens. (Greenwich) 2018, 20, 1430-1437. [CrossRef]

29. Koo, B.K.; Denenberg, J.O.; Wright, C.M.; Criqui, M.H.; Allison, M.A. Associations of perirenal fat thickness with renal and systemic calcified atherosclerosis. Endocrinol. Metab. (Seoul) 2020, 35, 122-131. [CrossRef] [PubMed]

30. Liu, K.H.; Chan, Y.L.; Chan, J.C.; Chan, W.B.; Kong, W.L. Mesenteric fat thickness as an independent determinant of fatty liver. Int. J. Obes. (London) 2006, 30, 787-793. [CrossRef] [PubMed]

31. Wueest, S.; Item, F.; Lucchini, F.C.; Challa, T.D.; Muller, W.; Bluher, M.; Konrad, D. Mesenteric fat lipolysis mediates obesity-associated hepatic steatosis and insulin resistance. Diabetes 2016, 65, 140-148. [CrossRef]

32. Ellrichmann, M.; Kapelle, M.; Ritter, P.R.; Holst, J.J.; Herzig, K.H.; Schmidt, W.E.; Schmitz, F.; Meier, J.J. Orlistat inhibition of intestinal lipase acutely increases appetite and attenuates postprandial glucagon-like peptide-1-(7-36)-amide-1, cholecystokinin, and peptide YY concentrations. J. Clin. Endocrinol. Metab. 2008, 93, 3995-3998. [CrossRef]

33. Guo, J.; Jou, W.; Gavrilova, O.; Hall, K.D. Persistent diet-induced obesity in male C57BL/6 mice resulting from temporary obesigenic diets. PLoS ONE 2009, 4, e5370. [CrossRef] [PubMed] 
34. Ipsen, D.H.; Lykkesfeldt, J.; Tveden-Nyborg, P. Molecular mechanisms of hepatic lipid accumulation in non-alcoholic fatty liver disease. Cell. Mol. Life Sci. 2018, 75, 3313-3327. [CrossRef]

35. Fabbrini, E.; Magkos, F.; Mohammed, B.S.; Pietka, T.; Abumrad, N.A.; Patterson, B.W.; Okunade, A.; Klein, S. Intrahepatic fat, not visceral fat, is linked with metabolic complications of obesity. Proc. Natl. Acad. Sci. USA 2009, 106, 15430-15435. [CrossRef]

36. Schindhelm, R.K.; Diamant, M.; Dekker, J.M.; Tushuizen, M.E.; Teerlink, T.; Heine, R.J. Alanine aminotransferase as a marker of non-alcoholic fatty liver disease in relation to type 2 diabetes mellitus and cardiovascular disease. Diabetes Metab. Res. Rev. 2006, 22, 437-443. [CrossRef]

37. Sorbi, D.; Boynton, J.; Lindor, K.D. The ratio of aspartate aminotransferase to alanine aminotransferase: Potential value in differentiating nonalcoholic steatohepatitis from alcoholic liver disease. Am. J. Gastroenterol. 1999, 94, 1018-1022. [CrossRef]

38. Sharma, B.R.; Oh, J.; Kim, H.A.; Kim, Y.J.; Jeong, K.S.; Rhyu, D.Y. Anti-obesity effects of the mixture of Eriobotrya japonica and Nelumbo nucifera in adipocytes and high-fat diet-induced obese mice. Am. J. Chin. Med. 2015, 43, 681-694. [CrossRef]

39. Lin, M.C.; Kao, S.H.; Chung, P.J.; Chan, K.C.; Yang, M.Y.; Wang, C.J. Improvement for high fat diet-induced hepatic injuries and oxidative stress by flavonoid-enriched extract from Nelumbo nucifera leaf. J. Agric. Food Chem. 2009, 57, 5925-5932. [CrossRef]

40. Wu, C.H.; Yang, M.Y.; Chan, K.C.; Chung, P.J.; Ou, T.T.; Wang, C.J. Improvement in high-fat diet-induced obesity and body fat accumulation by a Nelumbo nucifera leaf flavonoid-rich extract in mice. J. Agric. Food Chem. 2010, 58, 7075-7081. [CrossRef]

41. Czech, M.P. Insulin action and resistance in obesity and type 2 diabetes. Nat. Med. 2017, 23, 804-814. [CrossRef] [PubMed]

42. Shirosaki, M.; Goto, Y.; Hirooka, S.; Masuda, H.; Koyama, T.; Yazawa, K. Peach leaf contains multiflorin a as a potent inhibitor of glucose absorption in the small intestine in mice. Biol. Pharm. Bull. 2012, 35, 1264-1268. [CrossRef]

43. Huang, C.F.; Chen, Y.W.; Yang, C.Y.; Lin, H.Y.; Way, T.D.; Chiang, W.; Liu, S.H. Extract of lotus leaf (Nelumbo nucifera) and its active constituent catechin with insulin secretagogue activity. J. Agric. Food Chem. 2011, 59, 1087-1094. [CrossRef]

44. Yan, K.; Zhu, H.; Xu, J.; Pan, H.; Li, N.; Wang, L.; Yang, H.; Liu, M.; Gong, F. Lotus leaf aqueous extract reduces visceral fat mass and ameliorates insulin resistance in HFD-induced obese rats by regulating PPARgamma2 expression. Front. Pharmacol. 2017, 8, 409. [CrossRef]

45. Chen, H.W.; Yang, M.Y.; Hung, T.W.; Chang, Y.C.; Wang, C.J. Nelumbo nucifera leaves extract attenuate the pathological progression of diabetic nephropathy in high-fat diet-fed and streptozotocin-induced diabetic rats. J. Food Drug Anal. 2019, 27, 736-748. [CrossRef]

46. Du, H.; You, J.S.; Zhao, X.; Park, J.Y.; Kim, S.H.; Chang, K.J. Antiobesity and hypolipidemic effects of lotus leaf hot water extract with taurine supplementation in rats fed a high fat diet. J. Biomed. Sci. 2010, 17 (Suppl. 1), S42. [CrossRef]

47. Fruhwurth, S.; Vogel, H.; Schurmann, A.; Williams, K.J. Novel insights into how overnutrition disrupts the hypothalamic actions of leptin. Front. Endocrinol. (Lausanne) 2018, 9, 89. [CrossRef]

48. Yang, R.; Barouch, L.A. Leptin signaling and obesity: Cardiovascular consequences. Circ. Res. 2007, 101, 545-559. [CrossRef]

49. Fishman, S.; Muzumdar, R.H.; Atzmon, G.; Ma, X.; Yang, X.; Einstein, F.H.; Barzilai, N. Resistance to leptin action is the major determinant of hepatic triglyceride accumulation in vivo. FASEB J. 2007, 21, 53-60. [CrossRef]

50. Ziemke, F.; Mantzoros, C.S. Adiponectin in insulin resistance: Lessons from translational research. Am. J. Clin. Nutr. 2010, 91, 258S-261S. [CrossRef] [PubMed]

51. Fruhbeck, G.; Catalan, V.; Rodriguez, A.; Gomez-Ambrosi, J. Adiponectin-leptin ratio: A promising index to estimate adipose tissue dysfunction. Relation with obesity-associated cardiometabolic risk. Adipocyte 2018, 7, 57-62. [CrossRef]

52. Inoue, M.; Maehata, E.; Yano, M.; Taniyama, M.; Suzuki, S. Correlation between the adiponectin-leptin ratio and parameters of insulin resistance in patients with type 2 diabetes. Metabolism 2005, 54, 281-286. [CrossRef] 
53. Guo, F.; Yang, X.; Li, X.; Feng, R.; Guan, C.; Wang, Y.; Li, Y.; Sun, C. Nuciferine prevents hepatic steatosis and injury induced by a high-fat diet in hamsters. PLoS ONE 2013, 8, e63770. [CrossRef]

54. Bodis, K.; Roden, M. Energy metabolism of white adipose tissue and insulin resistance in humans. Eur. J. Clin. Invest. 2018, 48, e13017. [CrossRef]

55. Catalano, K.J.; Stefanovski, D.; Bergman, R.N. Critical role of the mesenteric depot versus other intra-abdominal adipose depots in the development of insulin resistance in young rats. Diabetes 2010, 59, 1416-1423. [CrossRef]

56. Item, F.; Konrad, D. Visceral fat and metabolic inflammation: The portal theory revisited. Obes. Rev. 2012, 13 (Suppl. 2), 30-39. [CrossRef]

57. Iniguez, M.; Perez-Matute, P.; Villanueva-Millan, M.J.; Recio-Fernandez, E.; Roncero-Ramos, I.; Perez-Clavijo, M.; Oteo, J.A. Agaricus bisporus supplementation reduces high-fat diet-induced body weight gain and fatty liver development. J. Physiol. Biochem. 2018, 74, 635-646. [CrossRef]

58. Kim, B.; Kwon, J.; Kim, M.S.; Park, H.; Ji, Y.; Holzapfel, W.; Hyun, C.K. Protective effects of Bacillus probiotics against high-fat diet-induced metabolic disorders in mice. PLoS ONE 2018, 13, e0210120. [CrossRef]

59. Lim, S.M.; Kim, E.; Shin, J.H.; Seok, P.R.; Jung, S.; Yoo, S.H.; Kim, Y. Xylobiose prevents high-fat diet induced mice obesity by suppressing mesenteric fat deposition and metabolic dysregulation. Molecules 2018, $23,705$. [CrossRef]

60. Li, Z.S.; Zheng, J.W.; Manabe, Y.; Hirata, T.; Sugawara, T. Anti-obesity properties of the dietary green alga, codium cylindricum, in high-fat diet-induced obese mice. J. Nutr. Sci. Vitaminol. (Tokyo) 2018, 64, 347-356. [CrossRef] [PubMed]

61. Kim, M.S.; Kim, B.; Park, H.; Ji, Y.; Holzapfel, W.; Kim, D.Y.; Hyun, C.K. Long-term fermented soybean paste improves metabolic parameters associated with non-alcoholic fatty liver disease and insulin resistance in high-fat diet-induced obese mice. Biochem. Biophys. Res. Commun. 2018, 495, 1744-1751. [CrossRef]

62. Song, Z.; Xiaoli, A.M.; Yang, F. Regulation and metabolic significance of de novo lipogenesis in adipose tissues. Nutrients 2018, 10, 1383. [CrossRef]

63. Berndt, J.; Kovacs, P.; Ruschke, K.; Kloting, N.; Fasshauer, M.; Schon, M.R.; Korner, A.; Stumvoll, M.; Bluher, M. Fatty acid synthase gene expression in human adipose tissue: Association with obesity and type 2 diabetes. Diabetologia 2007, 50, 1472-1480. [CrossRef]

64. Jiang, G.; Li, Z.; Liu, F.; Ellsworth, K.; Dallas-Yang, Q.; Wu, M.; Ronan, J.; Esau, C.; Murphy, C.; Szalkowski, D.; et al. Prevention of obesity in mice by antisense oligonucleotide inhibitors of stearoyl-CoA desaturase-1. J. Clin. Invest. 2005, 115, 1030-1038. [CrossRef] [PubMed]

65. Cheng, C.F.; Ku, H.C.; Lin, H. PGC-1alpha as a pivotal factor in lipid and metabolic regulation. Int. J. Mol. Sci. 2018, 19, 3447. [CrossRef]

66. Goto, T.; Lee, J.Y.; Teraminami, A.; Kim, Y.I.; Hirai, S.; Uemura, T.; Inoue, H.; Takahashi, N.; Kawada, T. Activation of peroxisome proliferator-activated receptor-alpha stimulates both differentiation and fatty acid oxidation in adipocytes. J. Lipid Res. 2011, 52, 873-884. [CrossRef] [PubMed]

67. Nair, A.B.; Jacob, S. A simple practice guide for dose conversion between animals and human. J. Basic Clin. Pharm. 2016, 7, 27-31. [CrossRef]

68. Van Gaal, L.F.; Broom, J.I.; Enzi, G.; Toplak, H. Efficacy and tolerability of orlistat in the treatment of obesity: A 6-month dose-ranging study. Orlistat dose-ranging study group. Eur. J. Clin. Pharmacol. 1998, 54, 125-132. [CrossRef]

69. Lodhi, I.J.; Yin, L.; Jensen-Urstad, A.P.; Funai, K.; Coleman, T.; Baird, J.H.; El Ramahi, M.K.; Razani, B.; Song, H.; Fu-Hsu, F.; et al. Inhibiting adipose tissue lipogenesis reprograms thermogenesis and PPARgamma activation to decrease diet-induced obesity. Cell Metab. 2012, 16, 189-201. [CrossRef] [PubMed]

70. Liu, K.; Lin, L.; Li, Q.; Xue, Y.; Zheng, F.; Wang, G.; Zheng, C.; Du, L.; Hu, M.; Huang, Y.; et al. Scd1 controls de novo beige fat biogenesis through succinate-dependent regulation of mitochondrial complex II. Proc. Natl Acad Sci USA 2020, 117, 2462-2472. [CrossRef] 
71. Hondares, E.; Rosell, M.; Diaz-Delfin, J.; Olmos, Y.; Monsalve, M.; Iglesias, R.; Villarroya, F.; Giralt, M. Peroxisome proliferator-activated receptor alpha (PPARalpha) induces PPARgamma coactivator 1alpha (PGC-1alpha) gene expression and contributes to thermogenic activation of brown fat: Involvement of PRDM16. J. Biol. Chem. 2011, 286, 43112-43122. [CrossRef]

72. Wang, W.; Seale, P. Control of brown and beige fat development. Nat. Rev. Mol. Cell Biol. 2016, 17, 691-702. [CrossRef]

Publisher's Note: MDPI stays neutral with regard to jurisdictional claims in published maps and institutional affiliations.

(C) 2020 by the authors. Licensee MDPI, Basel, Switzerland. This article is an open access article distributed under the terms and conditions of the Creative Commons Attribution (CC BY) license (http://creativecommons.org/licenses/by/4.0/). 